ably involved in the ATP binding and ATPase activity and in the interaction with nucleic acids. Whether these proteins are homologous in the sense that they have diverged from a common ancestral protein, or have acquired their similarity by convergence, is unknown.

We would like to thank Bertrand Seraphin for communication of the MSS116 sequence and Reinhard Dölz for assistance with computer programs.

Patrick Linder

Department of Microbiology,

Biozentrum, Basel, Switzerland

PaUl F. LASKO*

Michael Ashburner

Department of Genetics,

University of Cambridge,

Cambridge CB2 3EH, UK

Pascale Leroy

Immunogénétique Humaine,

Institut Pasteur, 75324 Paris, France

Peter J. Nielsen

Max-Planck-Institüt für Immunbiologie,

7800 Freiburg, FRG

KAYOKO NiSHI

JOACHIM SCHNIER

Department of Biological Chemistry,

University of California School of Medicine,

Davis, California 95616, USA

Piotr P. Slonimski

Centre de Génétique Moléculaire du CNRS,

91190 Gif-sur-Yvette, France

*To whom correspondence should be addressed.

1. Nielsen. P.J., McMaster, G.K. \& Trachsel, H. Nucleic Acids Res. 13, 6867-6880 (1985)

Nielsen, P.J. \& Trachsel, H. EMBO J. 7, 2097 (1988)

3. Linder, P.\& Slonimski, P.P. Proc. natn. Acad. Sci. U.S.A. (submitted).

4. Leroy, P. et al. Cell (submitted)

5. Ford, M.J., Anton, I.A. \& Lane, D.P. Nature 332, 736 (1988).

6. Lasko. P.F. \& Ashburner, M. Nature 335, 611-617 (1988)

7. Seraphin, B., Simon, M., Boulet, A. \& Faye. G. Nature (in the press).

8. Nishi, K., Morel-Deville, F., Hershey, J.W. B., Leighton, T. \& Schnier, J. Nature (in the press)

9. Hodgman, T.C. Nature 333, 22-23 (1988).

10. Hodgman, T.C. Narure 333, $578(1988)$

11. Lane. D. Nature 334, 478 (1988)

12. Dayhoff. M.O., Schwartz, R.M. \& Oncutt, B.C. in Atlas of Protein Sequence and Structure Vol. 5, Suppl. 3 (ed Dayhoff, M.O.) 345-352 (1978)

13. Walker, J.E., Saraste, M., Runswick, M.J. \& Gay, N.J. EMBOJ. 1, 945-951 (1982).

14. Ray, B.K. et al. J. biol. Chem. 260, 7651-7658 (1985).

15. Devereux, J., Haeberli, P. \& Smithies, O. Nucleic Acids Res. 12, 387-395 (1984)

\section{Plant competition}

SIR-Gaudet and Keddy ${ }^{1}$ claim to provide a general non-phenomenological, predictive tool for studying competition in natural communities. However, there are several problems with their approach.

First, analysis of the experimental data in inadequate. After testing 44 species, Gaudet and Keddy found a strong relationship between the phytometer biomass and the traits of the test species, and a relationship of similar strength when a different phytometer (Penthorum sedoides) was used with a subset of ten test species. They also found just as strong a relationship when they used traits of the test species grown in monoculture as predictors of the phytometer's biomass when it was grown with the test species. In all cases, however, Gaudet and Keddy failed to report or interpret the vector of multiple regression coefficients, which would indicate how, as a group, the traits define a good versus a bad competitor (for example, a good competitor has high above-ground biomass relative to belowground biomass). These coefficients can be interpreted much like the coefficients of one of the extracted axes from a principal component analysis (PCA). The difference is that in PCA each axis defines a particular, independent trend in a group of variables, while in multiple regression the one extracted axis defines how a group of variables acts togther in predicting a single, dependent variable. Thus, Gaudet and Keddy fall short of adequately describing the relationship between Lythrum salicaria and 44 competitors in a highnutrient soil, and leave us with only biomass as a crude predictor of competitive ability.

More important, Gaudet and Keddy fail to demonstrate how their technique has "the potential for predicting the outcome of multispecies competitive interactions". It seems reckless to assert that the ability to rank pairwise competition coefficients in a single set of carefully defined conditions will enable one to predict anything about higher-order interactions among species in a real multispecies setting. Even if one assumes no significant higher order interactions among species, the influence of habitat variation on pairwise competitive relationships must be considered.

Department of Zoology, Robert C. BAILEy

University of Western Ontario,

London, Ontario, Canada N6A 5B7

SIR-Gaudet and Keddy' claim to provide a tool for predicting the outcome of competition in multispecies communities. But there are problems with their study:

(1) The statistics used to demonstrate that there is a strong relationship between plant traits and competitive ability are invalid. This is because at the same time as the focal plant is being affected by its neighbours, the growth of the neighbours is being affected by the focal plant. The use of regression analysis is, therefore, not appropriate as the predictor variables are not independent of the response variables ${ }^{2-4}$.

(2) The finding that interspecific ability is related to plant size is not surprising because they equate competitive ability with the reduction in biomass of the target phytometer. There are many precedents for this type of definition; indeed, we use it in our own papers ${ }^{4.6}$. But such a definition gives particular weight to the effects of plant size $\mathrm{e}^{5}$ and by implication relative growth rate? If this were the only factor determining the outcome of competition between species over several generations, then communities would be dominated by those plants with the highest relative growth rates. This is clearly not the case.

(3) The use of biomass reduction as an index of competitive effect is unhelpful in explaining the role of competition in determining the structure of natural communities. Here the emphasis should be upon the effects of competition on the per capita rate of increase, which is not perfectly correlated with biomass since it also depends on many other variables including population interactions such as herbivory and mutualism. It is simply not possible to forecast the outcome of competition over several generations on the basis of short-term changes in biomass ${ }^{8}$.

Gaudet and Keddy provide no indication of how their results can be used to predict community structure.

The search for general principles in competition studies has met with greater success than indicated by the authors. The effects of competition with monocultures and simple mixtures of plants is becoming well understood ${ }^{9}$; various plant strategies have been identified ${ }^{7}$; and the role of resources in determining the structure of communities has also been investigated ${ }^{10}$. But it remains difficult to predict the outcome of competition in a particular natural community, which is inevitable given that communities can be highly complex, non-linear mutivariate systems which include variables that are by their nature unpredictable.

\section{L.G. FIRBANK}

Department of Science,

Cambridgeshire College of Arts and

Technology,

East Road, Cambridge CBI 1PT, UK

A.R. WATKINSON

School of Biological Sciences,

University of East Anglia,

Norwich NR4 7TJ, UK

SIR-Gaudet and Keddy argue ${ }^{1}$ that the study of interspecific competition in community ecology has failed to yield any general principles. This conclusion is incorrect. The point is not that studies have "yielded an overwhelming body of special cases", but rather that they have shown that the outcome of interspecific competition is contingent on the specific conditions under which an experiment is conducted. In particular, the starting density and frequency of competitors can alter the outcome. Replacement series experiments often fail to produce general results because they do not explore the full range of densities needed to determine the trajectory a two-species mixture may follow $^{\mathrm{ij}}$

The contingent nature of interspecific 